\title{
Is the trophic diversity of marine benthic consumers decoupled from taxonomic and functional trait diversity? Isotopic niches of Arctic communities
}

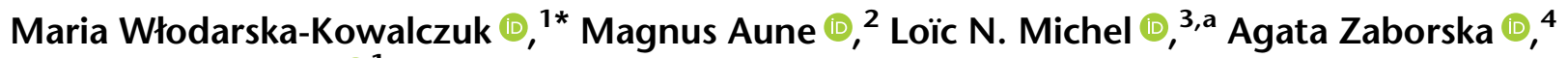 \\ Joanna Legeżyńska (i) ${ }^{1}$ \\ ${ }^{1}$ Department of Marine Ecology, Institute of Oceanology Polish Academy of Science, Sopot, Poland \\ ${ }^{2}$ Akvaplan-Niva, The Fram Centre, Tromsø, Norway \\ ${ }^{3}$ Laboratory of Oceanology, Freshwater and Oceanic Sciences Unit of reSearch (FOCUS), University of Liège, Liège, Belgium \\ ${ }^{4}$ Department of Marine Chemistry, Institute of Oceanology Polish Academy of Science, Sopot, Poland
}

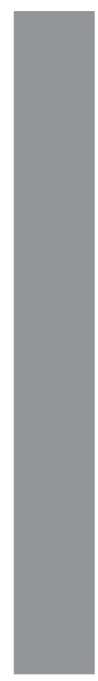

\begin{abstract}
It is predicted that a diverse array of functional traits in species-rich assemblages can lead to strong resource partitioning among coexisting species and moderate a wider spectrum of resource use. We compared two benthic communities in an Arctic fjord: a species-rich community (in an outer basin) and an impoverished community (in a glacially impacted bay) and explored (1) if high species richness was translated into high functional trait richness and (2) if high taxonomic and functional diversity promoted high trophic diversity in terms of resource use (indicated by isotopic niche measures). We documented higher functional trait richness in the outer basin (computed based on traits describing feeding mode, mobility, food source, body size and life habit), but the area occupied by consumers in the $\delta^{15} \mathrm{~N}$ vs. $\delta^{13} \mathrm{C}$ iso-space (a proxy for total trophic resource use) did not differ between the two sites. A wide array of functional traits used to acquire food may extend the benthic community trophic niche spatially (where and how animals forage) without impacting the isotopic niche breadth (in this system, mostly reflecting "what animals feed on") due to the relatively homogenous distribution of isotopic characteristics of detritus pool across vertical scales in marine sediments. Moreover, this trend could indicate that a species-poor community tends to exploit all the available food items, possibly due to the low food availability for primary consumers in a glacially impacted environment. Communities in glacial bays could therefore be particularly sensitive to future changes in glacial inputs and associated organic matter fluxes.
\end{abstract}

Understanding how diversity and community structure translate into ecosystem functioning (defined as the flow of energy and matter through its components) is one of the fundamental questions of ecology (Lawton 1994). Biodiversity effects on productivity and/or trophic efficiency can be mediated by niche differentiation or facilitation between species, leading to the performance of communities exceeding that which would be expected from the performance of individual species (Loreau and Hector 2001). Petchey and Gaston (2006) predicted that in species-rich assemblages intense competition for resources could induce a tendency among species to display a more diverse array of biological and ecological

*Correspondence: maria@iopan.gda.pl

Additional Supporting Information may be found in the online version of this article.

Present address:

alfremer, Centre de Bretagne, REM/EEP, Laboratoire Environnement Profond, Plouzané, France traits. Functional differences between species can lead to niche differentiation or facilitation. Species-specific nutritional niches and resource partitioning may moderate a wider spectrum of resource use (Godbold et al. 2009). Thus, understanding the effects of biodiversity on the trophic functioning of communities requires resolving the links among species richness, functional trait diversity, and resource use/trophic niche of the community as a whole. Isotopic niche metrics combined with functional trait-based analyses provide tools for exploring this issue.

It is increasingly recognized that a suite of functional traits determines community functioning better than the mere number of species (Hooper et al. 2005; Deraison et al. 2015). Functional trait diversity has been documented to have stronger effect than species richness on, e.g., benthic oxygen fluxes in marine sediments (Belley and Snelgrove 2016) or the productivity of rock pool macroalgae (Griffin et al. 2009). Furthermore, evidence suggests that species richness and functional diversity may even have different effects on community function in terms of biomass accumulation and productivity (Reich et al. 
2004). Most often, in natural communities, functional trait diversity tends to increase with increasing species richness (e.g., Hooper et al. 2005; Wiedmann et al. 2014). However, strong environmental filtering can limit the range of functional characteristics, and increasing species richness leads to a finer division of the available niche space rather than greater functional diversity (Hooper et al. 2005). Additionally, the strength and shape of the relationship between taxonomic and functional diversity depend on the extent of functional redundancy within the assemblage. In species-rich communities, species tend to play overlapping functional roles, which may induce saturation in trait values and thereby decrease the rate of increase in the relationship between taxonomic and functional diversity, with functional diversity ultimately leveling off toward asymptotic values (Micheli and Halpern 2005). Nonpositive relationships occurring in marine natural systems have been reported, e.g., by Belley and Snelgrove (2016) and Mindel et al. (2016).

For groups of individuals (populations or communities), Bearhop et al. (2004) introduced the concept of isotopic niche. Rigolet et al. (2015) stated that two-dimensional $\delta^{13} \mathrm{C}$ and $\delta^{15} \mathrm{~N}$ space combined and reflected several biological traits (as foraging behavior, feeding movements, and morphological characteristics) and interspecies relationships (as food competition or prey-predator pathways). Isotopic niche has been used as a proxy for the multidimensional space of a realized ecological niche, as it reflects the variability caused by both bionomic (related to consumed resources) and scenopoetic (related to habitat) factors (Newsome et al. 2007; Flaherty and Ben-David 2010). Layman et al. (2007a) proposed a series of metrics that described the trophic structure and diversity of communities based on the positions of organisms in isotopic space.

In this study, we focus on the interplay between different components of ecological diversity. We compare two benthic communities (species-rich and impoverished) and explore links among taxonomic richness, functional richness, and trophic diversity (depicted through the isotopic niche metrics). Specifically, we aim to answer two questions. First, we ask whether differences in taxonomic diversity lead to corresponding contrasts in functional diversity. We hypothesize (hypothesis 1) that higher species richness is correlated with higher functional trait diversity. Although intuitive, this relationship is not ubiquitous in complex natural systems (Hooper et al. 2005). Second, we ask whether an increase in taxonomic and functional diversity promotes resource use by the community. As more species are present in one of the sites and because they putatively exhibit a great diversity of food acquisition mechanisms (as pictured by functional traits), we hypothesize (hypothesis 2) that organisms living in the species-rich site exploit a greater range of different trophic resources, covering a wider isotopic niche and display higher trophic diversity, as indicated by higher values of isotopic niche metrics pertaining to how the different species segregate the available food items among themselves.

This study compared two localities in Arctic coastal waters that strongly differed in the taxonomic richness of benthic invertebrates (Włodarska-Kowalczuk and Węsławski 2008). Arctic glacial fjords offer natural steep environmental gradients created by the glacial inflows. The glacially impacted basins are characterized by reduced taxonomic diversity (due to chronic natural disturbance by the strong mineral sedimentation) compared to the nonimpacted species-rich communities (Włodarska-Kowalczuk et al. 2005, 2012). Although the patterns of taxonomic diversity have been thoroughly explored (e.g., Włodarska-Kowalczuk et al. 2005, 2007, 2012, 2013), neither the functional trait diversity metrics nor the isotopic niche characteristics of benthic communities have yet been documented in Arctic fjords. Our goal was to provide a view of how environmental disturbance could affect ecological interactions in Arctic fjord macrofauna, by connecting species diversity (linked with community resilience), lifestyle and energy acquisition mode diversity (pictured by functional traits), and resource use and partitioning that is of basic importance for organic matter fluxes in the fjord food web.

\section{Materials and methods}

\section{Sampling and laboratory analyses}

Two sites in Hornsund fjord (Spitsbergen) were selected based on previous species diversity reports (Włodarska-Kowalczuk and Węsławski 2008; Włodarska-Kowalczuk et al. 2013): an impoverished INNER site in a glacial bay $\left(15.34^{\circ} \mathrm{E}, 76.55^{\circ} \mathrm{N}\right)$ and a species-rich OUTER site at the fjord mouth $\left(16.30^{\circ} \mathrm{E}, 77.01^{\circ} \mathrm{N}\right)$. Benthic organisms for taxonomic and functional trait analyses were collected using a van Veen grab in 2005 (25 grabs at five stations at each site; Włodarska-Kowalczuk and Węsławski 2008), 2012, and 2013 (3 grabs at one station in each year and site). The samples were sieved with a $0.5-\mathrm{mm}$ sieve and fixed in buffered formalin. In the laboratory, all the macrobenthic individuals were identified and counted.

Samples of potential food sources (macroalgae, sediment organic matter, pelagic particulate organic matter, and tundra; Supporting Information Table S1) and macrofaunal consumers for the isotopic analyses (32 species at INNER site and 57 species at OUTER site) were collected at two sites in 2013. On board, the organisms were identified and kept in filtered seawater for several hours to allow gut clearance. From 1 to 120 individuals (Supporting Information Table S2) of the same taxon were pooled to obtain sufficiently large samples. In the laboratory, the samples were freeze-dried, homogenized, weighed into silver capsules (with $1 \mu \mathrm{g}$ accuracy), soaked in 2 mol L ${ }^{-1}$ hydrochloric acid to remove carbonates and dried at $60^{\circ} \mathrm{C}$ for $24 \mathrm{~h}$. The carbon and nitrogen stable isotope composition $\left(\delta^{13} \mathrm{C}\right.$ and $\left.\delta^{15} \mathrm{~N}\right)$ was measured using an elemental analyzer (Flash EA 1112 Series) combined with an isotopic ratio mass spectrometer (IRMS Delta V Advantage, Thermo Electron Corp.). Calcite (IAEA-CO-8), ammonium sulfate (IAEA-N-1), and L-glutamic acid (USGS40) were used as certified reference materials. 


\section{Taxonomic and functional trait diversity assessment}

The taxonomic diversity of the two sites was compared at a scale of a single sampling point (a sample) and a site. The sample diversity was expressed by the number of species per sample $(S)$ and by the Hurlbert rarefaction index (ES[100]). Species richness at the site scale was explored using species accumulation curves that described the observed (Sobs) or true species richness (Chao2; Chao 2005) as a function of the number of samples.

We used functional richness (FRic; Mason et al. 2005; Villéger et al. 2008) as a measure of functional diversity. To do so, we first compiled functional traits related to the trophic ecology of the 209 taxa (Macdonald et al. 2010; Fauchald and Jumars 1979; Feder and Matheke 1980; Degen and Faulwetter 2018; Supporting Information Table S3). The trait matrix was binary and consisted of 19 functional traits associated with five trait categories. The traits were feeding mode (suspension feeder, detritus feeder, carnivore, grazer/herbivore, and suctorial parasite), mobility (mobile, discretely mobile, and sedentary), food source (subsurface, surface, and epibenthic), body size (length: < $10 \mathrm{~mm}, 10-50 \mathrm{~mm}, 50-100 \mathrm{~mm}$, and > $100 \mathrm{~mm}$ ), and life habit (free-living, attached, burrow-dwelling, tubicolus, and parasitic). In cases where trait information was not available at the species level, information at a higher taxonomic level (genus or family) was used. FRic was calculated as the volume of the convex hull in multidimensional trait space, i.e., the volume of the functional space occupied by the species in a community (Villéger et al. 2008). First, a Gower dissimilarity matrix was computed based on the trait matrix. Principal coordinate analysis (PCoA) was then performed on the distance matrix, and the resulting PCoA axes represented the new trait values needed to calculate FRic (Laliberté and Legendre 2010). FRic is thus the volume encompassing the extreme trait values represented in a community. Consequently, species with nonextreme trait values have no impact on the FRic estimate.

Following a three-step procedure, we used a null model to investigate whether FRic values were higher or lower than expected by chance. First, we generated 10,000 artificial species assemblages based on the species from the actual species list. Each species assemblage consisted of 8-67 species (i.e., the range in species richness $[S R]$ in the collected samples). Second, we calculated the FRic of the artificial assemblages. Third, we compared real FRic values for the given $S R$ values to the corresponding null model values using a general linear model. To investigate whether the FRic $\sim S R$ relationships (real data and null model data) were linear or nonlinear, we used a generalized additive model (GAM). The linear regression slope, as inferred from a general linear model, was used to assess the rate of increase in FRic with increasing $S R$.

Differences in S, ES[100], and FRic between the two sites and among the three sampling years were tested using two-way univariate permutational analysis of variance (PERMANOVA) models (with two factors: site and year) based on a similarity matrix created from the Euclidean distances among the samples (Anderson et al. 2008).

\section{Isotopic niche characteristics assessment}

Isotopic spaces were built using the average values of $\delta^{13} \mathrm{C}$ and $\delta^{15} \mathrm{~N}$ for each species. Two descriptors of isotopic richness were computed: total areas of the convex hulls (TAs, i.e., convex polygons encompassing all species [Layman et al. 2007a] and standard ellipse areas SEAs [Jackson et al. 2011]). The SEA for bivariate data is comparable to the standard deviation for univariate data and is considered to be more robust to differences in sample size and less sensitive to extreme values than the TA. Species were categorized into three basic trophic groups: suspension feeders, deposit feeders, and carnivores. Both the convex hulls and standard ellipses were plotted for (1) all the species collected in each location and (2) each of the three functional groups separately. An estimator of the $S E A$ corrected for small sample size $\left(S E A_{\mathrm{C}}\right)$ was calculated, as some of the groups contained less than 30 data points (taxa).

Additionally, a number of descriptors of various facets of isotopic diversity (Layman et al. 2007a) were computed for the two sites: (1) $\delta^{15} \mathrm{~N}$ range $(N R)$, indicating food chain length; (2) $\delta^{13} \mathrm{C}$ range (CR), indicating the diversity of basal resources; (3) mean distance to a centroid $(C D)$, indicating the niche width and degree of dietary separation of the species; (4) mean nearest neighbor distance (MNND), a measure of density and clustering of species within a community; and (5) standard deviation of the nearest neighbor distance $(S D N N D)$, a measure of evenness of partial density and packing. Overall, these metrics reflect complementary facets of isotopic diversity: $N R$ and $C R$ mostly indicate the total isotopic space used, $C D$ depicts the degree of differentiation of species niches, and MNND and SDNND represent the regularity in the distribution of species niches. This complementarity allows for a complete and efficient description of the isotopic diversity of the studied communities.

For each isotopic metric, a Bayesian approach was used to represent the estimated (posterior) distribution of values. This approach takes into account the uncertainty connected with natural variability and allows for robust statistical comparisons between the communities. Direct pairwise comparisons of the isotopic metrics were performed by calculating the percentage of the model solutions (based on $10^{6}$ iterations) that differed between the sites. This percentage can be interpreted as a direct proxy for a probability that a given metric in one site is larger than in the other (Jackson et al. 2011; Reid et al. 2016). We defined a threshold value of $95 \%$ as indicative of a meaningful difference.

The calculations of ES[100] and the PERMANOVA tests were performed using Primer/PERMANOVA+, the species accumulation curves and the Chao2 were computed using EstimateS software v7.5. The trait-based metrics were calculated and assessed in R 3.4.1 using the packages FD for calculating FRic (Laliberté and Legendre 2010) and mgcv for the GAM estimation (Wood 2000). Layman's metrics were computed using the SIAR (stable isotope analysis in R) package v. 4.2.2, the SEAs were calculated using the SIBER (stable 
isotope Bayesian ellipses in R; Jackson et al. 2011) package v. 2.1.3 with R 3.4.3.

\section{Results}

Taxonomic and functional trait diversity

Both the $S$ and ES[100] were lower at the INNER site (mean $13.7 \pm 3.0 \mathrm{SD}$ and $8.9 \pm 1.6)$ than at the OUTER site $(53.3 \pm 5.8$ and $19.6 \pm 1.7$; Fig. 1B,C). The two-way PERMANOVA tests indicated significant effects of site and year, but the higher $\mathrm{CV}$ values indicated much stronger variability assigned to site than to year in both cases (Table 1). A total of 51 and 198 species were found, while 76 and 290 species were estimated by the Chao2 to occur at the INNER site and the OUTER site, respectively. The Sobs and Chao2 were higher at the OUTER site than at the INNER site across the whole accumulation curve (Fig. 1A). The $0.95 \mathrm{CI}$ of the Sobs at the INNER site did not overlap with that of the OUTER site, and neither did the $0.95 \mathrm{CI}$ of the Chao2, indicating significant differences between the two communities.

Lower values of FRic $(32.3 \pm 33.8)$ were noted at the INNER site than at the OUTER site $(430.8 \pm 84.9$; Fig. 1D). A two-way PERMANOVA test indicated significant effects of site and year, with a predominant effect of site indicated by higher a CV (Table 1). Nonlinear relationships were observed for the null model FRic values as functions of the corresponding $S R$ values. The actual FRic values for the given $S R$ values corresponded to those expected from the null models. The relationship between FRic and $S R$ was stronger at the INNER site $\left(R^{2}=0.72\right.$, $p<0.001)$ compared to the OUTER site $\left(R^{2}=0.27, p=0.002\right)$, and the increase in FRic per species in $S R$ (as indicated by regression slope values) was higher at the INNER site than that at the OUTER site (9.6 vs. 7.7; Fig. 1E).

\section{Isotopic niche characteristics}

The isotopic composition of the available food items did not vary between the sites, indicating a similar composition of baseline resources (Supporting Information Table S1). The standard ellipses and convex hulls plotted for the whole INNER and OUTER communities (all species) were similar in shape, with a shift toward lower $\delta^{13} \mathrm{C}$ values and slightly higher $\delta^{15} \mathrm{~N}$ values in the case of the INNER site (Fig. 2A). The total areas of the convex hulls (TA) were similar for the INNER $\left(30.80 \% 0^{2}\right)$ and OUTER $\left(33.80 \% \mathrm{o}^{2}\right)$ communities (Fig. 3B), as the probability of difference was $65 \%$. The standard ellipse areas were also similar at the INNER $\left(S E A_{\mathrm{C}}=8.58 \% \mathrm{o}^{2}\right)$ and the OUTER $\left(S E A_{\mathrm{C}}=6.43 \%{ }^{2}\right)$ localities (probability of difference: 92\%; Fig. 3A).

At the INNER site, the suspension feeders displayed a wider range of $\delta^{15} \mathrm{~N}$ values (Fig. 2E). At the OUTER site, most of the isotopic variability in the suspension feeder ellipse was driven by the $\delta^{13} \mathrm{C}$ values (ranging from $-22.2 \%$ to $-19.2 \%$ ). The standard ellipse was larger at the INNER site $\left(S E A_{C}=6.28 \% 0^{2}\right)$ than at the OUTER site $\left(S E A_{\mathrm{C}}=4.22 \% \mathrm{o}^{2}\right)$ in $95 \%$ of the model runs (Fig. 3A). The standard ellipses for the detritus feeders in the two sites were similar in shape in size, with the position of the INNER ellipse shifted toward lower values of $\delta^{13} \mathrm{C}$ (Fig. 2D). The model estimations suggested that the standard ellipse area was similar at the INNER $\left(S E A_{\mathrm{C}}=3.06 \% \mathrm{o}^{2}\right)$ and OUTER $\left(S E A_{\mathrm{C}}=2.71 \% \mathrm{o}^{2}\right)$ localities, as the probability of differences was only $51 \%$ (Fig. 3A). The standard ellipses for the carnivores in both sites were similar in shape, with the ellipse plotted for the INNER site extended more toward higher $\delta^{15} \mathrm{~N}$ values (with the amphipod Onisimus caricus having $\delta^{15} \mathrm{~N}$ values over $15 \%$; Fig. 2C). In addition, the model estimations suggested that the standard ellipse area was similar at the INNER $\left(S E A_{\mathrm{C}}=\right.$ $\left.7.39 \% 0^{2}\right)$ and $\operatorname{OUTER}\left(S E A_{\mathrm{C}}=5.96 \% \mathrm{oo}^{2}\right)$ localities, with a probability of differences of $62 \%$ (Fig. 3A).

Bayesian modeling suggested that none of the Layman's metrics differed between the two communities. The probabilities of difference were $64 \%$ for $N R, 55 \%$ for $C R, 79 \%$ for $C D$, $74 \%$ for $M N N D$, and $52 \%$ for $S D N N D$ (Fig. 3C-G).

\section{Discussion}

Although the two studied benthic communities clearly differed in terms of taxonomic and functional richness, no corresponding significant differences in the metrics describing isotopic niches were detected. Petchey and Gaston (2006) predicted that numerous species coexisting in biologically accommodated communities employed a diverse array of functional traits that facilitated their coexistence and the increased partitioning of the trophic niche. They hypothesized that the trophic niche of a whole community was defined by the complexity of trophic interactions and that a higher diversity of functional modes resulted in a wider trophic niche. Indeed, in the present study, the differences in taxonomic richness between the INNER and OUTER sites were mirrored by similar contrasts in functional richness. However, the $T A$ and SEA metrics indicated that the lower number of species co-occurring at the INNER locality exploited a trophic niche of the same width as the species-rich and functionally diverse community at the OUTER site. Although the first hypothesis (a positive relationship between taxonomic and functional diversity) can be confirmed, the second hypothesis (changes in trophic structure in response to higher species richness and functional trait diversity) needs to be rejected based on the results of the present study.

The low taxonomic diversity in the inner basin is dictated by physical stress mediated by high turbidity and sediment instabilities produced by glacial inflows (Włodarska-Kowalczuk et al. $2005,2007)$. Here, we suggest that these physical factors also modulate the FRic at the INNER site, as the species there are plausibly adapted to specific conditions and a high degree of environmental adversity. Strong environmental adversity is generally associated with underdispersion in species' traits, because the adaptation to these conditions entails particular combinations of such traits (Weiher and Keddy 1995) that, in the case of glacial bays, involve small body size, high mobility, and surface 

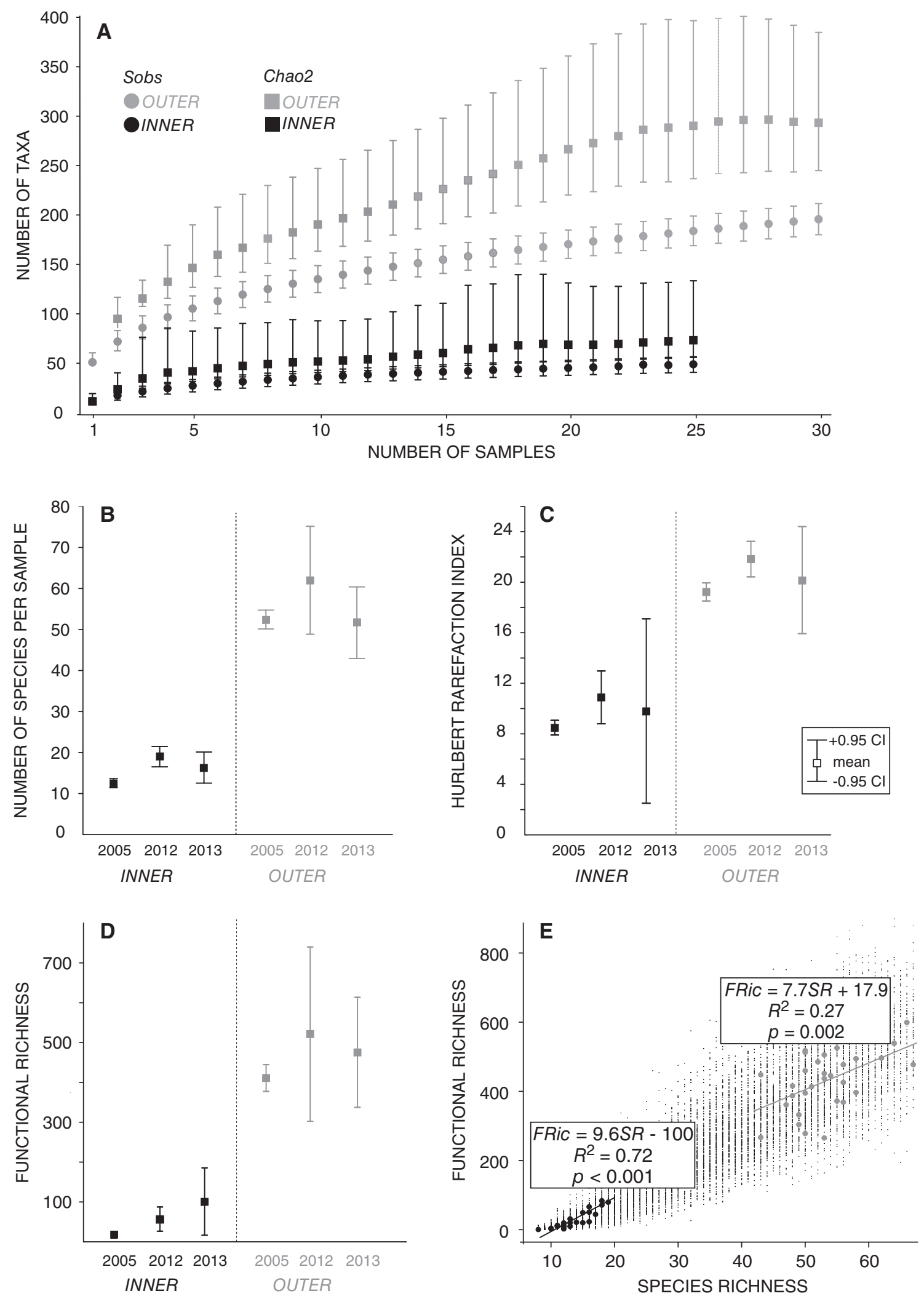

Fig. 1. Taxonomic and functional richness of the two sites: (A) species accumulation curves (plotted along with the $0.95 \mathrm{Cl}$ ) for the observed species richness (Sobs) and the estimated true species richness (Chao2), (B) the number of species per sample, (C). Hurlbert rarefaction for 100 individuals, and (D) the functional richness. The points on the plot $\mathbf{E}$ represent the values obtained from the null models, and the circles represent the values in real communities. The regression equations for the functional richness (FRic) to species richness (SR) for the two communities are presented in boxes. 
Table 1. Two-way PERMANOVA tests for differences in the number of taxa per sample (S), Hurlbert rarefaction (ES[100]), and functional richness (FRic) among years and sites.

\begin{tabular}{|c|c|c|c|c|c|c|c|}
\hline \multirow[b]{2}{*}{ Source } & \multirow[b]{2}{*}{ df } & \multicolumn{2}{|c|}{$s$} & \multicolumn{2}{|c|}{$E S[100]$} & \multicolumn{2}{|c|}{ FRic } \\
\hline & & psF & CV & psF & CV & psF & CV \\
\hline Site & 1 & $554.0^{* *}$ & 775.1 & $299.8^{* *}$ & 56.8 & $299.5^{* *}$ & 1.9 \\
\hline Year & 2 & $9.6^{* *}$ & 15.2 & $7.6^{*}$ & 1.6 & $8.2^{\star \star}$ & 0.1 \\
\hline Site $\times$ year & 2 & 1.3 & 1.0 & 0.1 & 0.4 & 0.2 & -0.0 \\
\hline Res & 49 & & 17.7 & & 2.4 & & 0.1 \\
\hline
\end{tabular}

PsF, PERMANOVA pseudo F; CV, component of variation.

Significant effects: ${ }^{*} p<0.05 ;{ }^{* *} p<0.001$.

detritus feeding (Włodarska-Kowalczuk et al. 2005). Such a consistent response of both species and functional diversity to disturbance or environmental variability has been reported in different systems (e.g., Flynn et al. 2009; Wiedmann et al. 2014). In the present study, the FRic for the given levels of $S R$ followed the null model predictions, confirming that the potentially higher functional richness embedded in larger species pool is indeed realized in the studied system. Habitat disturbance does not necessarily influence all facets of biodiversity in the same way, as it may be modified by other environmental constraints, e.g., by food availability. For instance, in a grassland study of ground beetle communities, a positive relationship between species diversity and the level of flood-induced disturbance was found, whereas no similar positive relationship was found for the FRic (Gerisch et al. 2012). The authors attributed the higher species diversity at the impacted sites to higher resource availability, whereas the lack of correspondingly high FRic values was explained by trait filtering. These effects differed from the glacial disturbance case, as the higher slope of the FRic $\sim S R$ regression lines in the INNER (compared to the OUTER) site indicated that the glacial bay community was still far from approaching saturation level in functional trait richness. In contrast, the addition of new species in a glacial bay increased the functional diversity, with a higher rate than that at the OUTER site, which agreed with previous claims of higher functional redundancy in undisturbed fjord basins (Włodarska-Kowalczuk et al. 2012).

The standard ellipses and convex hulls of the two sites in isospace were of similar size but clearly shifted along the $\delta^{13} \mathrm{C}$ axis. Since the isotopic composition of the food items was similar at the two sites (Supporting Information Table S1), this shift likely indicates differences in the relative contributions of the exploited food sources. Lower values of $\delta^{13} \mathrm{C}$ observed in the INNER community suggest a dependence on ${ }^{13} \mathrm{C}$-depleted material, such as terrestrial-derived organic matter. High water turbidity impedes marine production in glacial bays (Piwosz et al. 2009), whereas glacial runoff is an important source of subfossil organic carbon that can be incorporated by microorganisms and then transferred to higher trophic levels (Lydersen et al. 2014). Larger contributions of marine organic carbon (especially that derived from macroalgae) in the productive outer basin could result in high $\delta^{13} \mathrm{C}$ values in the OUTER benthic consumers.
The standard ellipses plotted for the suspension feeders and detritus feeders at the INNER site covered narrow $\delta^{13} \mathrm{C}$ ranges that were highly overlapped, which implies that both groups exploit the same basal resources. As the availability of fresh organic matter from pelagic production is low, suspension feeders living in glacial bays must rely on resuspended sediment organic matter. Material deposited in surface sediments is often reworked by bacteria that increase the $\delta^{15} \mathrm{~N}$ values of consumers (Iken et al. 2010), as was observed in the INNER suspension feeders. The use of resuspended or advected reworked organic matter seems to be a common strategy of suspension feeders at high latitudes, allowing their persistence despite the temporal or permanent scarcity of fresh marine production (Gillies et al. 2012). The standard ellipse for the OUTER suspension feeders was widened along the $\delta^{13} \mathrm{C}$ axis, which is likely a consequence of the availability of diverse food sources differing in their carbon isotopic ratios (a larger availability of fresh material from marine production compared to the INNER site).

The standard ellipses for the carnivores were similar in size and positioned in markedly higher $\delta^{15} \mathrm{~N}$ ranges than the ellipses plotted for the primary consumers in both sites. Layman et al. $(2007 b)$ predicted that a reduction in prey diversity should result in a decline of the SEA of the respective carnivores and reported such a relationship for fish. In the present study, the OUTER benthic community had far higher taxonomical and functional diversity, but the primary consumers spanned an isotopic niche that was similar in size, as did the carnivores. In contrast to the primary consumers, the carnivores may find favorable feeding conditions in the inner basins of the fjords. Marine zooplankton confronted with glacial meltwaters can be stunned or killed by osmotic shock and sink to the bottom (Zajączkowski and Legeżyńska 2001). Moreover, live euphausiids, chaetognaths, and pelagic amphipods avoid surface meltwaters and tend to aggregate close to the seabed. In addition, carrion feeders may exploit zoobenthic taxa damaged or dislodged as a result of sediment iceberg scouring. The high $\delta^{15} \mathrm{~N}$ values observed in the INNER carnivores may be explained by feeding on local primary consumers enriched isotopically due to an intensive microbial recycling of sediment organic matter and/or by the advection of zooplankton prey. 

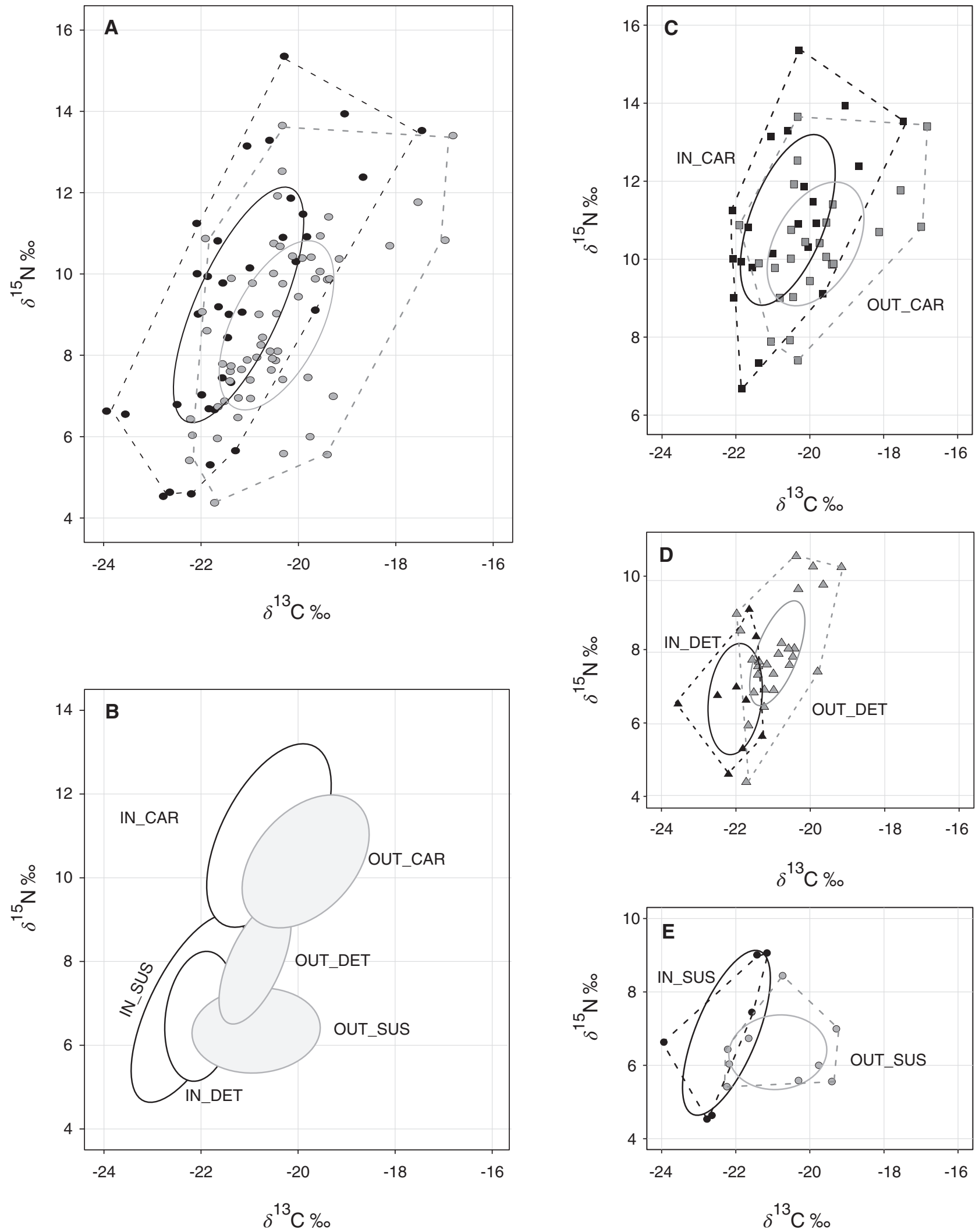

Fig. 2. Standard ellipses (full lines) and convex hulls (dashed lines) at two sites (INNER, black; OUTER, gray) for (A) all species, (B) all trophic groups, (C) carnivores (CAR), (D) detritus feeders (DET), and (E) suspension feeders (SUS). 

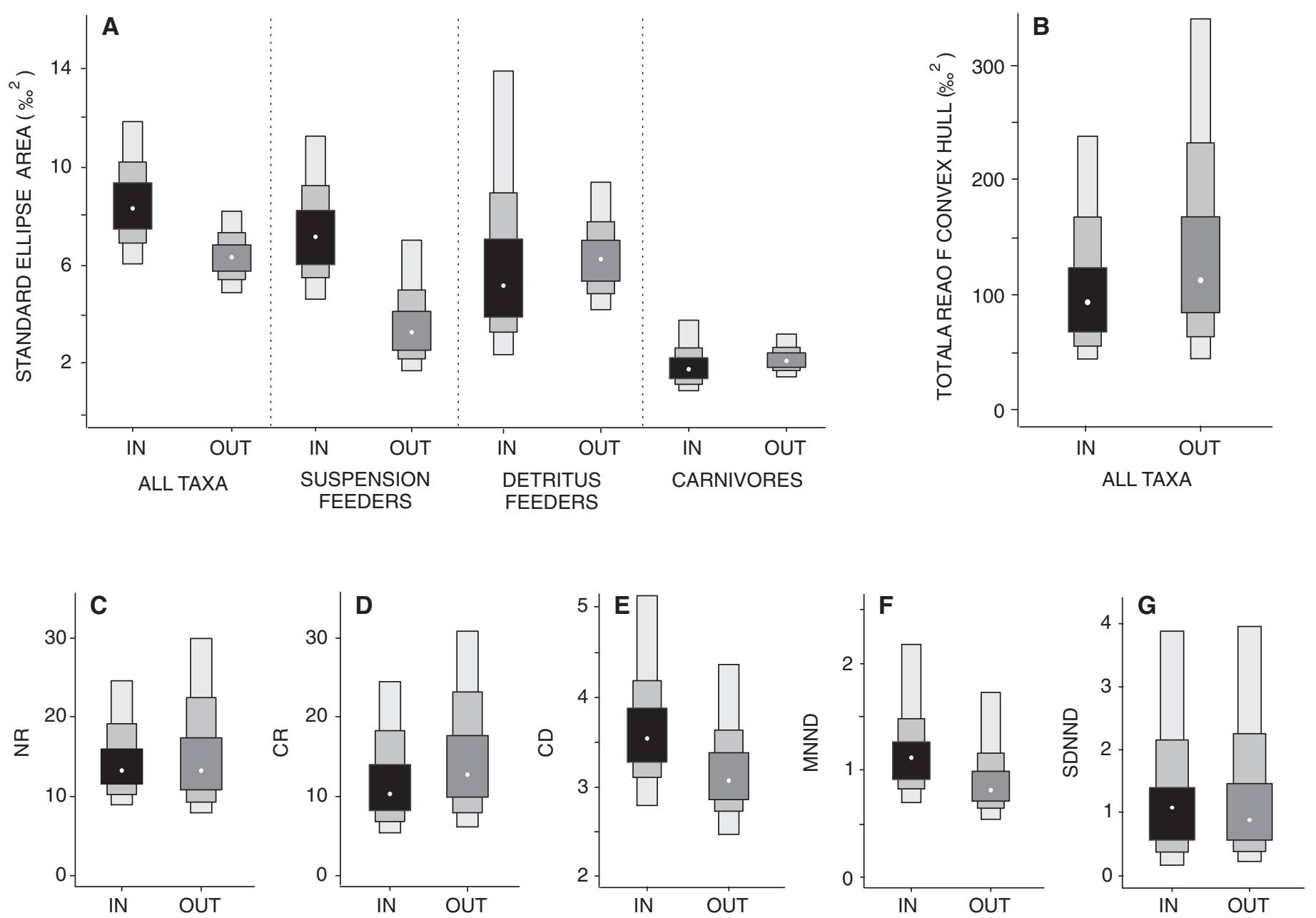

Fig. 3. Boxplots of the (A) standard ellipse area, (B) convex hull area and Layman metrics $([\mathbf{C}] N R,[\mathbf{D}] C R,[\mathbf{E}] C D,[\mathbf{F}] M N N D$, and $[\mathbf{G}] S D N N D)$ at two sites (IN, INNER; OUT, OUTER). The white dots are modes, and the boxes are credibility intervals (50\% black or dark gray boxes, $75 \%$ intermediate gray boxes, and $95 \%$ light gray boxes) of the posterior probability distributions of the model solutions.

In addition to niche width, the similarity of Layman's metrics in the two communities suggests that the isotopic niche structure is comparable in the two localities. No strong contrasts in the $C D$ and $M N N D$ metrics hinted at a similar magnitude of species separation in the isotopic space exhibited in the two studied benthic communities, both belonging to detritus-based food webs. Compared to primary producers, detritus is a more temporally stable reservoir of energy that sustains resilient food chains and is relatively insensitive to short-term environmental fluctuations (Moore et al. 2004). Although the detritus pool may appear homogenous, it often encompasses diverse components with different particle sizes, chemical compositions and origins, including dead phytoplankton and zooplankton, fecal pellets, terrestrial organic matter, and bacteria (Beaulieu 2002; Campanyà-Llovet et al. 2017). Detrital-based benthic food webs often contain consumers with a high degree of feeding plasticity (Moore et al. 2004; North et al. 2014). Deposit feeders can be selective to some degree, as indicated, e.g., by the different composition of their fecal pellets compared to surrounding sediments (Jumars and Eckman 1983; Lopez and Levinton 1987). Godbold et al. (2009) explored niche separation in depositfeeding echinoderms and documented a high degree of niche overlap at shallow depths compared to that in the deep sea and claimed that more plentiful food decreased interspecific competition for food resources and reduced the potential for fine-scale niche separation and feeding selectivity in coastal waters. Disturbance can keep the populations below carrying capacity and thus release species competition pressure and niche specialization (Taupp et al. 2017). The opposite effects of high disturbance (potentially releasing niche specialization; Taupp et al. 2017) and low food availability (potentially increasing niche specialization; Godbold et al. 2009) in a glacial bay may have overlapped, and in effect, both systems (INNER and OUTER) exhibited similar levels of species niche separation.

Similar trophic niche widths (as indicated by stable isotopebased metrics) despite the differences in taxonomic and 
functional trait composition and diversity documented for marine benthic invertebrates (present study) have also been reported for other systems: freshwater fish and invertebrates (Kupilas et al. 2016; Pool et al. 2016) and coral fish (Gajdzik et al. 2018). Pool et al. (2016) performed meta-analyses of published data on 63 freshwater fish communities, comparing their species, functional traits and trophic diversities using similar metrics as those used in the present study (number of species, FRic and TA). They assumed that the more specious communities with a more diverse array of biological and ecological traits would use a wider spectrum of resources, as indicated by the area occupied in iso-space. They found a strong positive relationship between taxonomic and functional diversity, but the links between the two and trophic diversity (indicated by isotopic niche width) were much weaker. They concluded that the communities' trophic diversity was driven mostly by system-specific factors that influence the architecture of trophic interactions irrespective of the taxonomic identity of the community components. The insensitivity of trophic niche breadth to environmentally driven changes in species composition and richness has also been reported for benthic communities in European rivers undergoing restoration programs (Kupilas et al. 2016) and in coral reef fish assemblages living in environmentally distinct coral reefs subjected to various levels of anthropogenic disturbance (Gajdzik et al. 2018).

Trophic niche includes several dimensions that define what, where, and when an animal or a group of animals forages (Nordström et al. 2010). Rigolet et al. (2015) claimed that a two-dimensional isotopic niche inherently combined several dimensions of the realized trophic niche of each species, such as foraging behavior, feeding movements, morphological characteristics of the feeding apparatuses, and inter-species relationships. However, it is debatable how much of the actual trophic niche is depicted in a two-dimensional isotopic niche. In our study, two detritus-based benthic communities that differed largely in terms of species functional trait diversity exploited isotopic niches of the same sizes. This suggests that widening the array of functional traits employed by a community did not increase the isotopic niche extent. Godbold et al. (2009) claimed that competition among coastal waters deposit feeders is low and that individual species are likely to adopt different feeding strategies (e.g., particle size, differences in mobility, and feeding depth) to utilize different fractions of the same detrital food source rather than seek other food sources. Additionally, Karlson et al. (2015) observed an overlap of isotopic niches in three studied native Baltic Sea deposit feeders but stated that this did not exclude resource partitioning in space. The distribution of functional traits in the two communities suggests that subtle differences in detritus acquisition within the sediment occurred among the species constituting the two studied communities, e.g., there were more deeply burrowing and sedentary species in the OUTER basin (Supporting Information Table S3). The insensitivity of the isotopic niche metrics to such changes in feeding traits may result from the relatively homogenous isotopic composition of the sediments in both localities. Neither Zaborska et al. (2018) nor Koziorowska et al. (2016) reported much variability in the $\delta^{13} \mathrm{C}$ or $\delta^{15} \mathrm{~N}$ values along the vertical profiles in sediment cores collected in Spitsbergen fjords. Thus, the total extent of the isotopic niche, mostly defining, in our system, "on what" the community as a whole feeds, remained the same regardless of the strong functional trait diversity (defining "where" and "how" animals forage) differences. It must be noted that the present findings rely on results from one fjord system, and it is recommended to test these ideas in other fjords and on the wider scale in other soft-bottom benthic systems with clear gradients of taxonomic and functional trait diversity.

Moore et al. (2004) stated that detritivore diversity affected the quantity and quality of decomposed detritus. Laboratory and field studies have suggested that decomposer species richness defines the rate at which leaf matter is broken down in streams (Moore et al. 2004). Regarding the marine subtidal benthos, a higher taxonomic diversity coupled with an increased variety of functional modes used to acquire food can also lead to increased organic carbon consumption and organic matter mineralization. This can be mediated via the extension of the spatial niches that can be reached by the community members (e.g., by increasing the sediment depth penetrated by the community) without increasing the array of food sources that are utilized. Similar observations (spatial partitioning of the same resources allowing the coexistence of more species) have been reported for Anolis lizards feeding on tree branches at various heights (Schoener 1974) and for pelagic-feeding damselfish foraging in different parts of a reef habitat (Gajdzik et al. 2016). Our results therefore suggest that Arctic fjord basins that are not glacially impacted are more likely to support higher benthic secondary productivity (as reported by Górska and Włodarska-Kowalczuk 2017). The community as a whole can increase its resource use if species use different resources or if they use the same resources but at different points in time or space (Hooper et al. 2005). Moreover, the communities from the parts of the fjords that were not glacially impacted showed more functional diversity and redundancy, which could increase their resilience to future changes. The subtidal communities from the glacially impacted parts of the fjords, conversely, live in areas characterized by extreme environmental conditions that are very likely to show changes that are strong and difficult to predict in the near future. These communities seem to rely on a limited food supply (as suggested by the higher overlap between the isotopic niches of detritus and suspension feeders), and their lower functional diversity could limit the way in which they can exploit the food supply. In this context, future climate change-induced modifications of glacier melting and therefore organic matter fluxes might have particularly strong effects on these communities and impair the ecological functioning in the glacially impacted basins of Arctic fjords. 


\section{References}

Anderson, M. J., R. N. Gorley, and K. R. Clarke. 2008. PERMANOVA+ for PRIMER: Guide to software and statistical methods. Primer-E.

Bearhop, S., C. E. Adams, S. Waldron, R. A. Fuller, and H. MacLeod. 2004. Determining trophic niche width: A novel approach using stable isotope analysis. J. Animal Ecol. 73: 1007-1012. doi:10.1111/j.0021-8790.2004.00861.x

Beaulieu, S. E. 2002. Accumulation and fate of phytodetritus on the sea floor. Oceanogr. Mar. Biol. Annu. Rev. 40: 171232. doi:10.1201/9780203180594.ch4

Belley, R., and P. V. Snelgrove. 2016. Relative contributions of biodiversity and environment to benthic ecosystem functioning. Front. Mar. Sci. 3: 242. doi:10.3389/fmars.2016.00242

Campanyà-Llovet, N., P. V. Snelgrove, and C. C. Parrish. 2017. Rethinking the importance of food quality in marine benthic food webs. Prog. Oceanogr. 156: 240-251. doi:10.1016/ j.pocean.2017.07.006

Chao, A. 2005. Species estimation and applications, p. 79077916. In N. Balakrishnan, C. B. Read and B. Vidakovic [eds.], Encyclopedia of statistical sciences. Wiley.

Degen, R., and S. Faulwetter. 2018. The Arctic traits database; [accessed 2018 August 13]. Available from www.univie.ac. at/arctictraits

Deraison, H., I. Badenhausser, N. Loeuille, C. Scherber, and N. Gross. 2015. Functional trait diversity across trophic levels determines herbivore impact on plant community biomass. Ecol. Lett. 18: 1346-1355. doi:10.1111/ele.12529

Fauchald, K., and P. A. Jumars. 1979. The diet of worms: A study of polychaete feeding guilds. Oceanogr. Mar. Biol. Annu. Rev. 17: 193-284.

Feder, H. M., and G. E. M. Matheke. 1980. Subtidal benthos. Chapter 9. Port Valdez, Alaska: Environmental Studies 1976-1979. Institute of Marine Sciences, University of Alaska, p. 237-324.

Flaherty, E. A., and M. Ben-David. 2010. Overlap and partitioning of the ecological and isotopic niches. Oikos 119: 1409-1416. doi:10.1111/j.1600-0706.2010.18259.x

Flynn, D. F., and others. 2009. Loss of functional diversity under land use intensification across multiple taxa. Ecol. Lett. 12: 22-33. doi:10.1111/j.1461-0248.2008.01255.x

Gajdzik, L., E. Parmentier, N. Sturaro, and B. Frédérich. 2016. Trophic specializations of damselfishes are tightly associated with reef habitats and social behaviours. Mar. Biol. 163: 249. doi:10.1007/s00227-016-3020-X

Gajdzik, L., E. Parmentier, L. N. Michel, N. Sturaro, K. Soong, G. Lepoint, and B. Frédérich. 2018. Similar levels of trophic and functional diversity within damselfish assemblages across indo-Pacific coral reefs. Functional Ecol. 32: 13581369. doi:10.1111/1365-2435.13076

Gerisch, M., V. Agostinelli, K. Henle, and F. Dziock. 2012. More species, but all do the same: Contrasting effects of flood disturbance on ground beetle functional and species diversity. Oikos 121: 508-515. doi:10.1111/j.1600-0706.2011.19749.x
Gillies, C. L., J. S. Stark, G. J. Johnstone, and S. D. Smith. 2012. Carbon flow and trophic structure of an Antarctic coastal benthic community as determined by $\delta 13 \mathrm{C}$ and $\delta 15 N$. Estuar. Coast. Shelf Sci. 97: 44-57. doi:10.1016/j. ecss.2011.11.003

Godbold, J. A., R. Rosenberg, and M. Solan. 2009. Speciesspecific traits rather than resource partitioning mediate diversity effects on resource use. PLoS One 4: e7423. doi: 10.1371/journal.pone.0007423

Górska, B., and M. Włodarska-Kowalczuk. 2017. Food and disturbance effects on Arctic benthic biomass and production size spectra. Prog. Oceanogr. 152: 50-61. doi:10.1016/j. pocean.2017.02.005

Griffin, J. N., V. Méndez, A. F. Johnson, S. R. Jenkins, and A. Foggo. 2009. Functional diversity predicts overyielding effect of species combination on primary productivity. Oikos 118: 37-44. doi:10.1111/j.1600-0706.2008.16960.x

Hooper, D. U., and others. 2005. Effects of biodiversity on ecosystem functioning: A consensus of current knowledge. Ecol. Monogr. 75: 3-35. doi:10.1890/04-0922

Iken, K., B. Bluhm, and K. Dunton. 2010. Benthic food-web structure under differing water mass properties in the southern Chukchi Sea. Deep-Sea Res. II Top. Stud. Oceanogr. 57: 71-85. doi:10.1016/j.dsr2.2009.08.007

Jackson, A. L., R. Inger, A. C. Parnell, and S. Bearhop. 2011. Comparing isotopic niche widths among and within communities: SIBER-stable isotope Bayesian ellipses in R. J. Animal Ecol. 80: 595-602. doi:10.1111/j.1365-2656.2011.01806.x

Jumars, P. A., and J. E. Eckman. 1983. In G. T. Rowe [ed.], Spatial structure within benthic communities. Wiley \& Sons.

Karlson, A. M., E. Gorokhova, and R. Elmgren. 2015. Do depositfeeders compete? Isotopic niche analysis of an invasion in a species-poor system. Sci. Rep. 5: 9715. doi:10.1038/srep09715

Koziorowska, K., K. Kuliński, and J. Pempkowiak. 2016. Sedimentary organic matter in two Spitsbergen fjords: Terrestrial and marine contributions based on carbon and nitrogen contents and stable isotopes composition. Cont. Shelf Res. 113: 38-46. doi:10.1016/j.csr.2015.11.010

Kupilas, B., N. Friberg, B. G. McKie, M. A. Jochmann, A. W. Lorenz, and D. Hering. 2016. River restoration and the trophic structure of benthic invertebrate communities across 16 European restoration projects. Hydrobiologia 769: 105-120. doi:10.1007/s10750-015-2569-6

Laliberté, E., and P. Legendre. 2010. A distance-based framework for measuring functional diversity from multiple traits. Ecology 91: 299-305. doi:10.1890/08-2244.1

Lawton, J. H. 1994. What do species do in ecosystems? Oikos 71: $367-374$. doi: $10.2307 / 3545824$

Layman, C. A., D. A. Arrington, C. G. Montaña, and D. M. Post. 2007a. Can stable isotope ratios provide for community-wide measures of trophic structure? Ecology 88: 42-48. doi: 10.1890/0012-9658

Layman, C. A., J. P. Quattrochi, C. M. Peyer, and J. E. Allgeier. $2007 b$. Niche width collapse in a resilient top predator 
following ecosystem fragmentation. Ecol. Lett. 10: 937-944. doi:10.1111/j.1461-0248.2007.01087.x

Lopez, G. R., and J. S. Levinton. 1987. Ecology of depositfeeding animals in marine sediments. Q. Rev. Biol. 62: 235-260. doi:10.1086/415511

Loreau, M., and A. Hector. 2001. Partitioning selection and complementarity in biodiversity experiments. Nature 412: 72-76. doi:10.1038/35083573

Lydersen, C., and others. 2014. The importance of tidewater glaciers for marine mammals and seabirds in Svalbard, Norway. J. Mar. Syst. 129: 452-471. doi:10.1016/j.jmarsys.2013.09.006

Macdonald, T., B. Burd, V. Macdonald, and A. Van Roodselaar. 2010. Taxonomic and feeding guild classification for the marine benthic macroinvertebrates of the strait of Georgia, British Columbia. Can. Tech. Rep. Fisheries Aquat. Sci. 2874: 4-62.

Mason, N. W. H., D. Mouillot, W. G. Lee, and J. B. Wilson. 2005. Functional richness, functional eveness and functional divergence: The primary components of functional diversity. Oikos 111: 112-118. doi:10.1111/j.0030-1299.2005.13886.x

Micheli, F., and B. S. Halpern. 2005. Low functional redundancy in coastal marine assemblages. Ecol. Lett. 8: 391-400. doi:10.1111/j.1461-0248.2005.00731.X

Mindel, B. L., F. C. Neat, C. N. Trueman, T. J. Webb, and J. L. Blanchard. 2016. Functional, size and taxonomic diversity of fish along a depth gradient in the deep sea. PeerJ 4: e2387. doi:10.7717/peerj.2387

Moore, J. C., and others. 2004. Detritus, trophic dynamics and biodiversity. Ecol. Lett. 7: 584-600. doi:10.1111/j.1461-0248. 2004.00606.x

Newsome, S. D., C. Martinez del Rio, S. Bearhop, and D. L. Phillips. 2007. A niche for isotopic ecology. Front. Ecol. Environ. 5: 429-436. doi:10.1890/060150.1

Nordström, M., P. Lindblad, K. Aarnio, and E. Bonsdorff. 2010. A neighbour is a neighbour? Consumer diversity, trophic function, and spatial variability in benthic food webs. J. Exp. Mar. Biol. Ecol. 391: 101-111. doi:10.1016/j.jembe.2010. 06.015

North, C. A., J. R. Lovvorn, J. M. Kolts, M. L. Brooks, L. W. Cooper, and J. M. Grebmeier. 2014. Deposit-feeder diets in the Bering Sea: Potential effects of climatic loss of sea icerelated microalgal blooms. Ecol. Appl. 24: 1525-1542. doi: 10.1890/13-0486.1

Petchey, O. L., and K. J. Gaston. 2006. Functional diversity: Back to basics and looking forward. Ecol. Lett. 9: 741-758. doi:10.1111/j.1461-0248.2006.00924.x

Piwosz, K., W. Walkusz, R. Hapter, P. Wieczorek, H. Hop, and J. Wiktor. 2009. Comparison of productivity and phytoplankton in a warm (Kongfsjorden) and cold (Hornsund) Spitsbergen fjord in mid-summer 2002. Polar Biol. 32: 549-559. doi:10.1007/s00300-008-0549-2

Pool, T. K., J. Cucherousset, S. Boulêtreau, S. Villéger, A. L. Strecker, and G. Grenouillet. 2016. Increased taxonomic and functional similarity does not increase the trophic similarity of communities. Glob. Ecol. Biogeogr. 25: 46-54. doi:10.1111/geb.12384

Reich, P. B., D. Tilman, S. Naeem, D. S. Ellsworth, J. Knops, J. Craine, D. Wedin, and J. Trost. 2004. Species and functional group diversity independently influence biomass accumulation and its response to $\mathrm{CO}_{2}$ and N. Proc. Natl. Acad. Sci. 101: 10101-10106. doi:10.1073/pnas.0306602101

Reid, W., C. Sweeting, B. Wigham, R. McGill, and N. Polunin. 2016. Isotopic niche variability in macroconsumers of the east scotia ridge (Southern Ocean) hydrothermal vents: What more can we learn from an ellipse? Mar. Ecol. Prog. Ser. 542: 13-24. doi: $10.3354 /$ meps 11571

Rigolet, C., É. Thiébaut, A. Brind'Amour, and S. F. Dubois. 2015. Investigating isotopic functional indices to reveal changes in the structure and functioning of benthic communities. Functional Ecol. 29: 1350-1360. doi:10.1111/1365-2435.12444

Schoener, T. W. 1974. Resource partitioning in ecological communities. Science 185: 27-39. doi:10.1126/science. 185.4145.27

Taupp, T., C. Hellmann, R. Gergs, C. Winkelmann, and M. A. Wetzel. 2017. Life under exceptional conditions-Isotopic niches of benthic invertebrates in the estuarine maximum turbidity zone. Estuaries Coasts 40: 502-512. doi:10.1007/ s12237-016-0163-4

Villéger, S., N. W. Mason, and D. Mouillot. 2008. New multidimensional functional diversity indices for a multifaceted framework in functional ecology. Ecology 89: 2290-2301. doi:10.1890/07-1206.1

Weiher, E., and P. A. Keddy. 1995. Assembly rules, null models, and trait dispersion: New questions from old patterns. Oikos 74: 159-164. doi:10.2307/3545686

Wiedmann, M. A., M. Aschan, G. Certain, A. Dolgov, M. Greenacre, E. Johannesen, B. Planque, and R. Primicerio. 2014. Functional diversity of the Barents Sea fish community. Mar. Ecol. Prog. Ser. 495: 205-218. doi:10.3354/meps10558

Włodarska-Kowalczuk, M., T. H. Pearson, and M. A. Kendall. 2005. Benthic response to chronic natural physical disturbance by glacial sedimentation in an Arctic fjord. Mar. Ecol. Prog. Ser. 303: 31-41. doi:10.3354/meps303031

Włodarska-Kowalczuk, M., M. Szymelfenig, and M. Zajączkowski. 2007. Dynamic sedimentary environments of an Arctic glacier-fed river estuary (Adventfjorden, Svalbard). II. Meioand macrobethic fauna. Estuarine Coastal Shelf Sci. 74: 274-284. doi:10.1016/j.ecss.2007.04.017

Włodarska-Kowalczuk, M., and J. M. Węsławski. 2008. Mesoscale spatial structures in soft-bottom macrozoobenthic communities: Effects of physical control and impoverishment. Mar. Ecol. Prog. Ser. 356: 215-224. doi:10.1016/j. ecss.2007.04.015

Włodarska-Kowalczuk, M., P. E. Renaud, J. M. Węsławski, S. K. Cochrane, and S. G. Denisenko. 2012. Species diversity, functional complexity and rarity in Arctic fjordic versus open shelf benthic systems. Mar. Ecol. Prog. Ser. 463: 73-87. doi:10.3354/meps09858 
Włodarska-Kowalczuk, M., J. Pawłowska, and M. Zajączkowski. 2013. Do foraminifera mirror diversity and distribution patterns of macrobenthic fauna in an Arctic glacial fjord? Mar. Micropaleontol. 103: 30-39. doi:10.1016/j.marmicro.2013. 07.002

Wood, S. N. 2000. Modelling and smoothing parameter estimation with multiple quadratic penalties. J. R. Stat. Soc. Series B Stat. Methodol. 62: 413-428. doi:10.1111/1467-9868.00240

Zaborska, A., M. Włodarska-Kowalczuk, J. Legeżyńska, E. Jankowska, A. Winogradow, and K. Deja. 2018. Sedimentary organic matter sources, benthic consumption and burial in West Spitsbergen fjords-signs of maturing of Arctic fjordic systems? J. Mar. Syst. 180: 112-123. doi:10.1016/ j.jmarsys.2016.11.005

Zajączkowski, M., and J. Legeżyńska. 2001. Estimation of zooplankton mortality caused by an Arctic glacier outflow. Oceanologia 43: 342-352.

\section{Acknowledgments}

We wish to thank Małgorzata Goeringer-d'Oedenberg, Aleksandra Winogradow, and Kajetan Deja for their help with the laboratory analyses. This study was funded by the National Science Centre, Poland (decision 2012/05/B/NZ8/02652, 4Age and decision 2016/23/B/NZ8/02410, $A B e F u n$ ) and the Polish-Norwegian Research Programme (project contract POL-NOR/199377/91/2014, GLAERE). M.A. was supported by the Norwegian Ministry of Foreign Affairs project CoArc.

\section{Conflict of Interest}

None declared.

Submitted 19 August 2018 Revised 17 December 2018 and 27 February 2019 Accepted 15 March 2019 Associate editor: Thomas Kiørboe 